\title{
The Study of Phenomenology, Family Factors, Functioning and Quality of Life in Childhood and Adolescent Depression
}

\author{
Alka A. Subramanyam ${ }^{1}$, Rajesh S. Narwade ${ }^{2}$, Bhagyashree H. Gaikwad ${ }^{3}$, Shipra Singh ${ }^{4}$, \\ Ravindra M. Kamath ${ }^{5}$ \\ ${ }^{1}$ Associate Professor \\ ${ }^{2,3}$ Speciality Medical Officer \\ ${ }^{4}$ Senior Resident \\ ${ }^{5}$ Professor and Head \\ Department of Psychiatry, B.Y.L. Nair Ch. Hospital \& T. N. Medical College, Mumbai. \\ Corresponding author: Bhagyashree Gaikwad \\ Email-bgaikwad79@yahoo.com
}

\begin{abstract}
Background and Objectives: Depression is a common psychiatric illness. The illness can present as a simple sadness to a major depressive disorder or even bipolar disorder. It is also found to affect children and adolescents. The aims and objectives of our study were, to assess the phenomenology, family factors, quality of life and functional status of children and adolescents with depression.

Methodology: Subjects diagnosed with depression, before 18 years of age, were recruited in the study. Parents and children were interviewed. Demographic details were taken. Scales i.e. Children Depression Inventory, Family Assessment Device, The PedsQL core generic scale and Children's Global Assessment scale were applied.

Results: Females had slightly higher scores on CDI. On using Pearson's correlation test significant correlations were found between the Family Assessment Device and PedsQL scale and CDI scale.

Conclusion: In the population under study, the family functioning was found to be unhealthy in families of girls with depression, versus families in which boys had depression. Overall depressive features were less in families with better affective responsiveness and affective involvement. In families who did not use problem solving as coping, somatic complaints were more. Better expression of emotions and behavioral control, was found in families having clear role definition.
\end{abstract}

Keywords: Children and adolescents, quality of life, family factors, depression.

(Paper received $-20^{\text {th }}$ November 2018 , Peer review completed $-8^{\text {th }}$ December 2018)

(Accepted $-10^{\text {th }}$ December 2018)

\section{INTRODUCTION}

Depression is a common psychiatric illness, affecting more than 300 million people of all ages globally. World Health Organization, states that depression is the leading cause of disability as measured by years lived with disability (YLD) and fourth leading contributor to global disease burden. Around $3-4 \%$ of India's 100 crores plus population suffer from a major mental disorder. In the southeast Asian region, $11 \%$ of DALY's and 27\% of YLD's are attributed to neuropsychiatric disease [1]. Hence, depression as an illness is an absolute cause of concern.

The clinical spectrum of the illness can range from simple sadness to a major depressive disorder or sometimes to bipolar disorder [2]. Depression in adolescents is a disabling condition that is associated with serious long-term morbidities and even suicide [3]. About $5 \%$ of the general population of children and 
adolescents may experience depression at any given point in time4 and its prevalence continues to rise [3]. Although depression is common among children and adolescents, it is still frequently unrecognized [2]. Depression is treatable but depressed children and adolescents may present with different behaviour than those of depressed adults. Hence, child and adolescent psychiatrists, caution parents to be acquainted with the signs of depression at any given point in time [4]. Children younger than seven years may not be able to describe their internal mood state and may express their distress through vague somatic symptoms or pain, irritable mood, anger outbursts and hostile behaviour.

Jacob and others [5] reported that while western societies may view depression as a medical problem that requires professional attention, more traditional societies assume depressive symptoms as social problems or as emotional reactions to situations. Similarly, in India, depression has been considered as a major health problem, but the treatment seeking remains rare. People deny psychological distress and instead interpret such distress as somatic illness taking help for same [6].

Prevalence estimates of unipolar depression vary with the time of reference and method of assessment. The reported point prevalence rates (30-day or 1 year) of major depressive disorder in non-referred samples range between $0.4 \%$ and $2.5 \%$ in children, and between $0.7 \%$ and $9.8 \%$ in adolescents [7-8]. Incidence of childhood depression is $4-8 \%$. However, studies from India found it to be $0.1 \%$ (Bangalore) and $0.16 \%$ (North India) and more common in females, with a male/female ratio of 1:2. Elevated risk for the disorder begins in the early teens, and continues to rise in a linear fashion throughout adolescence, with lifetime rates estimated to range from $15 \%$ to $25 \%$ by late adolescence [9-11]. These prevalence estimates of adolescent depression are comparable to the lifetime rates reported in adults, suggesting that, the rates of depression begin to plateau by early adult life [10-11]. The data also indicate that, for a substantial proportion of adult cases, the onset occurred during adolescence [12]. The prevalence of depression in youngsters is even greater when minor depression and sub-syndromal depressive symptoms are considered.

The effect of family factors on depression has been well documented in adults. Studies in children and adolescents, using both symptom assessment and diagnostic criteria, have linked depression to lower socioeconomic status. Lower socioeconomic status may be a marker or a specific risk factors associated with depression, rather than exerting a direct influence. This is because low socioeconomic status is associated with high levels of chronic stress due to economic difficulties, adverse environmental conditions and family disruption [13]. Research has found that $20 \%$ to $50 \%$ of children and adolescent with a family history of depression or other mental health disorder have depression in early childhood or adolescence. Children with pre-pubertal onset of depression are at higher risk of developing other mental health disorder in adulthood, such as bipolar disorders [14]. In a family study results showed that relatives of depressed children have higher rate of major depressive disorder.

Diagnosis of primary depressive mood disorders requires that physicians rule out depression from other medical causes, and when present, the condition is referred to as depressive mood disorder secondary to other medical conditions. Depressive disorders in children and adolescents are associated with significant economic and social burden on individuals, families, and societies. Moreover, other factors frequently associated with depression, such as comorbid psychiatric disorders, poor family functioning, low socioeconomic status, and exposure to stressful life events they all impact psychosocial functioning of a person. Depression in children and adolescents is also associated with an increased frequency of suicidal behaviours, delinquency, and alcohol and drug use. Prospective studies found that after recovery, children and adolescents continue to manifest impaired psychosocial functioning in multiple domains [15].

Since, depression can have an impact on his/her future well being, there is a need for appropriate and timely intervention for early diagnosis and treatment for the same. Although, there is no agreed upon definition for, "quality of life" the World Health Organization (WHO) conceptualizes it as the result of the interaction between social, economic, environmental, and health factors that affect human and social development. It is a broad definition which encompasses physical health, psychological wellbeing, level of independence, social relations, personal beliefs and the relationship with the environment, being determined by the capacity to obtain necessary resources and maintain autonomy and independence in accordance with age [16]. 
The aims and objective of the current study was to study the phenomenology, family factors, quality of life and the functional status of patients with childhood and adolescent depression.

\section{METHODOLOGY}

We designed an observational cross-sectional study, which was conducted in a tertiary care hospital in Mumbai. The study began after taking the approval of our Institutional Ethics Committee. The study included children and adolescents with depression, recruited from outpatient department of school mental health clinic, in Department of psychiatry, of a tertiary care hospital in Mumbai. We enrolled children/adolescent diagnosed with depression according to DSM 5 [17] criteria. Consecutive type of nonprobability sampling was used for the selection of subjects. Based on the hospital data of past 3 years, the cases of childhood and adolescent depression is found to be 1-2 per month. Since this is periodic sample, minimum 30 diagnosed cases of childhood and adolescent depression were taken in the 9 months study duration.

Our sample included, children/adolescents between 8-18 years of age referred for academic difficulties. Parents willing to give informed consent and children giving ascent. Children/adolescent diagnosed with major depressive disorder according to DSM 5 criteria. We excluded children and adolescents with any comorbid chronic /acute other medical or psychiatric condition like bronchial asthma, epilepsy, substance abuse, ADHD, ASD or any other neurodevelopmental disorder etc.

A total of 30 subjects diagnosed with depression, by psychiatrist as per DSM- 5 criteria, before 18 years of age, were recruited in the study. The parents and children were interviewed by the trainee psychiatrist conducting the study. The interview consisted of a filling of semi-structured proforma which included demographic details of the participants followed by administration of the rating scales.

\section{Instruments used in the study}

1. The Children's Depression Inventory (CDI): It is a psychological assessment that rates the severity of symptoms related to depression and/or dysthymic disorder in children and adolescents. The CDI was developed by American clinical psychologist Maria Kovacs, $\mathrm{PhD}$, and was firstpublished in 1979. It was developed by using the Beck Depression Inventory (BDI) of 1967 for adults as a model and "starting point." The assessment is now in its second edition. The CDI is a 27-item scale that is self-rated and symptom-oriented. Clients rate themselves based on how they feel and think, with each statement being identified with a rating from 0-2. Cronbach's alpha used to obtain high reliability measures, across one group of nine studies, alpha measures were 0.71 0.89 , reflecting good internal consistency. Regarding the short factor subscales alpha reliability measures for internal consistency reliability were 0.59-0.68 [18-19].

2. Family Assessment Device (FAD): The Family Assessment device based on the McMaster model of family functioning [MMFF]. The model evolved from previous work of Epstein, Sigal and Rakoff 1962, Westely and Epstein 1969. It describes structural and organizational properties of the family group and patterns of transaction among family member which helps distinguish between healthy and unhealthy family. Family Assessment Device is a 53-item questionnaire which constitutes a part of the larger Family Assessment Device. Each item is rated from 1 (Strongly Agree) to 4 (Strongly Disagree). The questionnaire takes approximately 15-20 minutes to complete. A series of studies have investigated the reliability and validity of the McMaster Family Assessment Device (FAD). The results indicated that the FAD has: (a) adequate test retest reliability, (b) low correlations with social desirability, (c) moderate correlations with other selfreport measures of family functioning, and (d) differentiates significantly between clinician-rated healthy and unhealthy families. Cut-off scores for identifying healthy and unhealthy families are developed which have adequate sensitivity and specificity [20-21].

3. The PedsQL (pediatric quality of life) core generic scales (PedsQL): The PedsQL measurement model, is a modular approach to measure health related quality of life (HRQOL) in healthy children and adolescent and those with acute and chronic health conditions. The PedsQL measurement model integrates seamlessly both generic core scales and disease specific modules 
into one measurement system. It contains 23 items, taking only 4 to 5 minutes to complete and designed for community, school, clinically pediatrics populations. It is multidimensional assessing physical, emotional, social and school functioning [22-23].

4. Children's Global Assessment Scale (CGAS): The Children's Global Assessment Scale (CGAS) is an adaptation of global assessment scale developed by Endicott et. al. (1976). The CGAS comprises of one item that is rated on a 100-point scale. The instrument contains behaviourally oriented descriptive example, it has no sub scale, raters assign one score ranging from 1-100. Test retest intra-class correlation across a 6-month interval ranged from 0.69 to 0.95 , intra-class correlation across raters at two occasions were 0.84 to 0.85 , the CGAS correlated significantly with other clinician rated measures of impairment and correlation ranged from 0.76 to 0.92 . A cut-off value of 60 or lower on the CGAS is indicative of definite impairment [24-25].

\section{STATISTICAL ANALYSIS}

The data was studied using statistical software SPSS-Version 20. Qualitative and demographic variable was analysed using descriptive statistics. The relationship between the study variable were computed using relevant inferential statistics. All the scales were described with frequency, mean, standard deviation. Pearson's correlation test was used for finding the co-relation of various scales.

\section{RESULTS}

Through our study, we have tried to understand the dynamic relationship between various factors that could be causative for the onset depression in an early age. Through the data given below, we have represented how, the phenomenology of the illness, family dynamics can or does influence the functioning and quality of life of children and an adolescent. We take a close look, as to how each factor is interwoven and independently associated with depression.

Table 1 - Mean scores and range on all the scales

\begin{tabular}{|c|c|c|c|c|}
\hline & Minimum & Maximum & Mean & Std. Deviation \\
\hline $\begin{array}{l}\text { Children Depression } \\
\text { Inventory (CDI) }\end{array}$ & 21 & 46 & 28.53 & 5.619 \\
\hline \multicolumn{5}{|c|}{ Pediatric scale of Quality of Life (PedsQL) } \\
\hline $\begin{array}{l}\text { About My Health And } \\
\text { Activities (AMHAA) }\end{array}$ & 28 & 81 & 47.93 & 14.607 \\
\hline About My Family (AMF) & 0 & 65 & 29.92 & 12.705 \\
\hline $\begin{array}{c}\text { How I Get Along With } \\
\text { Others (HIGAWO) }\end{array}$ & 25 & 85 & 52.50 & 19.946 \\
\hline About School (AS) & 20 & 85 & 39.50 & 11.697 \\
\hline $\begin{array}{c}\text { Children Global Assessment } \\
\text { Scale (CGAS) }\end{array}$ & & & 67.93 & 6.068 \\
\hline \multicolumn{5}{|c|}{ Family Assessment Device (FAD) } \\
\hline Problem Solving & & & 1.90 & 0.310 \\
\hline Communication & & & 1.93 & 0.517 \\
\hline Roles & & & 1.85 & 0.516 \\
\hline Affective Responsiveness & & & 1.89 & 0.330 \\
\hline Affective Involvement & & & 1.79 & 0.634 \\
\hline Behavioural Control & & & 1.82 & 0.487 \\
\hline General Functioning & & & 1.81 & 0.420 \\
\hline
\end{tabular}


Most of our study population belonged to the age group of 14 to 17 years (56.7\%) followed by age group 10 to 13 years $(43.3 \%)$. Thus, most of them were school going between class fifth to tenth class. We observed a higher percentage of females $(60 \%)$ compared to males, depicting more females come to psychiatric OPD with depressive symptoms, i.e. the illness being more common in this gender. Nuclear family type $(80 \%)$ was observed to be common. Also, most of them belonged to the $25,000-35,000$ income group (43.3\%) followed by $(15,000$ to 25,000$)$ income group $(33.3 \%)$. We had $16.7 \%$ of our study population with family history of psychiatric illness, predisposing children to mental health issues. On comparing the male-female data on the Children Depression Inventory we observed that the scores were higher for depression in the age group of 14 to 17 years followed by being slightly higher for the females, though statistical significance was not observed. In our study, we observed that, on the Pediatric Quality of life scale the social functioning (problem with how I get along with others-HIGWO) was more affected in females, whereas the physical functioning (problem about my health and activities-AMHAA), emotional functioning (problem about my feelings-AMF) and functioning at school (problem at school-AS) is more hampered in males. We also found that physical, emotional, social functioning and functioning at school was more affected among the 14 to 17 years of age group. This difference however, did not have statistical significance.

On children's global assessment scale, we found that there was a higher (16.7\% males, $11.1 \%$ females) trend of some noticeable problem (60-51) i.e. variable functioning with sporadic difficulties or symptoms in several but not all social area in males followed by the same high trend in some problem (70-61) i.e. some difficulty in single area, general functioning is well in males (58.3\% males, $44.4 \%$ females). Which suggests that there are more chances of them going unnoticed. Also, we observed that the overall functioning was more hampered in the age group of 14 to 17 years. But it was statistically insignificant.

Thus, the above findings support the fact that depression in children presents as problem with academic functioning, irritable behaviour, anger issues, defiance, somatization, poor peer relations and above all difficulty expressing their emotions.

On Family assessment device, we found high unhealthy functioning in females on the problem solving (33.3\% females, $16.7 \%$ males), roles (22.2\% females, $16.7 \%$ males), affective responsiveness $(27.8 \%$ females, $25 \%$ males) and behavioural control (55.6\% females, $41.7 \%$ males) sub-domains, and males had high unhealthy functioning on communication ( $41.7 \%$ males, $33.3 \%$ females) and affective involvement (41.7\% males, $27.8 \%$ females) but the difference was statistically insignificant. We also observed that there was a higher trend of depressive features in children from nuclear families and in families with history of psychiatric illness.

Table 2 - Correlation between the various scales

\begin{tabular}{|c|c|c|c|}
\hline FAS & & CDI $(\mathrm{n}=30)$ & CGAS $(\mathrm{n}=30)$ \\
\hline Problem Solving & $\mathrm{r}$ value & -0.266 & 0.095 \\
\cline { 2 - 4 } & $\mathrm{p}$ value & 0.156 & 0.616 \\
\hline \multirow{2}{*}{ Communication } & r value & -0.305 & -0.167 \\
\cline { 2 - 4 } & $\mathrm{p}$ value & 0.102 & 0.378 \\
\hline \multirow{2}{*}{ Roles } & r value & -0.09 & 0.214 \\
\cline { 2 - 4 } & $\mathrm{p}$ value & 0.635 & 0.256 \\
\hline Affective & r value & -0.413 & -0.011 \\
\cline { 2 - 4 } Responsiveness & $\mathrm{p}$ value & $0.023^{*}$ & 0.955 \\
\hline Affective & r value & -0.440 & 0.011 \\
\cline { 2 - 4 } Involvement & $\mathrm{p}$ value & $0.015^{*}$ & 0.954 \\
\hline Behaviour Control & r value & 0.3 & 0.083 \\
\cline { 2 - 4 } & $\mathrm{p}$ value & 0.107 & 0.665 \\
\hline General & r value & -0.180 & 0.174 \\
\cline { 2 - 4 } Functioning & $\mathrm{p}$ value & 0.341 & 0.358 \\
\hline \multicolumn{2}{|c|}{${ }^{*}$ Correlation is significant at $\mathrm{p} \leq 0.05$ level } \\
\hline
\end{tabular}


On corelating the sub-domains of Family assessment device with CDI, we found significant correlation between the affective responsiveness and affective involvement with depression scores on Children Depressive Illness. This suggests that people with experience of inappropriate affect among the family members and unhealthy affective involvement i.e. no value regarding each other's concerns and activities lead to higher depression scores on CDI.

Table 3 - Correlation between the sub-domains of FAS and sub-domains of Peds QL scale

\begin{tabular}{|c|c|c|c|c|c|}
\hline \multicolumn{2}{|c|}{$\begin{array}{l}\text { Subscales of FAS and Ped QL } \\
(\mathrm{n}=30)\end{array}$} & AMHAA & AMF & HIGAWO & AS \\
\hline \multirow[t]{2}{*}{ Total Score } & rvalue & 0.315 & 0.333 & 0.153 & 1 \\
\hline & $\mathrm{p}$ value & 0.09 & 0.072 & 0.419 & \\
\hline \multirow{2}{*}{ Problem Solving } & r value & -0.376 & -0.05 & -0.265 & -0.233 \\
\hline & $\mathrm{p}$ value & $0.041^{*}$ & 0.791 & 0.157 & 0.215 \\
\hline \multirow[t]{2}{*}{ Communication } & $\mathrm{r}$ value & -0.321 & -0.087 & -0.403 & -0.131 \\
\hline & $p$ value & 0.084 & 0.647 & $0.027^{*}$ & 0.490 \\
\hline \multirow[t]{2}{*}{ Roles } & rvalue & 0.176 & 0.392 & -0.165 & -0.013 \\
\hline & $\mathrm{p}$ value & 0.351 & $0.032^{*}$ & 0.383 & 0.946 \\
\hline \multirow[t]{2}{*}{ Affective Responsiveness } & r value & -0.069 & 0.182 & -0.149 & -0.086 \\
\hline & $\mathrm{p}$ value & 0.718 & 0.336 & 0.431 & 0.650 \\
\hline \multirow[t]{2}{*}{ Affective Involvement } & rvalue & -0.173 & 0.086 & -0.145 & -0.171 \\
\hline & $\mathrm{p}$ value & 0.360 & 0.651 & 0.444 & 0.366 \\
\hline \multirow[t]{2}{*}{ Behaviour Control } & r value & -0.09 & -0.064 & -0.058 & -0.576 \\
\hline & $\mathrm{p}$ value & 0.636 & 0.737 & 0.760 & $0.001^{*}$ \\
\hline \multirow[t]{2}{*}{ General Functioning } & rvalue & -0.1 & 0.206 & -0.1 & -0.322 \\
\hline & $\mathrm{p}$ value & 0.6 & 0.274 & 0.599 & 0.082 \\
\hline
\end{tabular}

On, correlating sub-domains of Family Assessment Device and sub-domains of Pediatric Quality of life scale we found following significant correlations. The problem-solving attitude in the family i.e. resolving issues and preserving family's integrity and functioning impacts child's cognitive development and helps him or her deal better with life problems. Thus, somatization and bodily complaints seem to be an outcome of lack of problem-solving attitude in the family. $(p=0.041)$. A healthy communication style within the family is necessary for children and adolescents to perform social interactions and maintain peer relations. Thus, lack of strong peer relation and unhealthy social behaviour could be an outcome of less clear and lack of direct communication practices among the family members. Clearer the communication style at home, lesser are the problems with social functioning. $(p=0.027)$. Defined roles in family determines, that responsibility is delivered better among the family members. This creates an atmosphere such that one can better emote their emotion. Hence, emotional functioning and regulation becomes better $(p=0.032)$. Similarly, adequate expression of emotions within the family members leads to regulation of behaviour at home, which translates into better behaviour at school too $(p=0.001)$.

\section{DISCUSSION}

Globally, up to $15 \%$ of children and adolescents have some symptoms of depression. Five percent of those are between 9 to 17 years of age and they meet the criteria for major depressive disorder $[1,4]$ and $3 \%$ of adolescents have dysthymic disorder [26]. On our comparison of male-female data on the CDI scale we saw, the scores were higher for depression in the age group of 14 to 17 years followed by being slightly higher for the females. Though statistical significance was not observed. The incidence of depressive disorders markedly increases after puberty. After, 14 years of age, depressive disorders are found to be two times more common in girls compared to boys, possibly because of the differences in the coping styles or the hormonal changes during puberty [4]. Researchers have reported that in the pre-pubertal age, the depression rates for boys and girls are similar, and that they are doubled in females after puberty. Females are at a higher risk of first onset of major depression from early adolescence until their mid-50's and have a 
lifetime depression rate of 1.7 to 2.7 -fold greater than males [27-28]. Crowe and others [29] report that depressed girls are more likely to have internal symptoms such as feeling lonely and unhappy, crying and hating themselves. The study also concluded that for both the adolescent girls and boys, the most common reported characteristics of depression includes interpersonal (social withdrawal, irritability and loneliness) and thought processing symptoms (difficulties with concentration and indecisiveness). In above findings, we observed that on the Pediatric Quality of life scale, the social functioning was more affected in females, whereas the physical functioning, emotional functioning and functioning at school was more hampered in males. We also found that these four levels of functioning were more affected in adolescents belonging to $14-17$ years age group. Though we did not find any statistical significance between the two.

On, children's global assessment scale we found that males mostly belonged to the category of some problem and some noticeable problem, both in which single or some aspects of social functioning are affected but the overall general functioning is good, which means that they are likely to go undetected. Adolescence is a critical time of development and it signifies a period of high risk for depression. At this stage of development, depressive symptoms are often dismissed or ignored as signs of adolescence or teenage behaviour. Depressed mood has been referred as a common experience during adolescence [3031]. We also observed that there was a higher trend of depressive features in nuclear family and families with history of psychiatric illness. Studies in children and adolescents, using both symptom assessment and diagnostic criteria, have linked depression to lower socioeconomic status. This is possibly because low socioeconomic status is associated with high levels of chronic stress due to economic difficulties, adverse environmental conditions and family disruption [13].

A study showed that those with high number of psychosocial risks in the family, had higher scores, but it decreased as the number of protective factors (Family provides structure, limits, rules, monitoring, and predictability, Supportive relationships with family members, clear expectations for behaviour and values) increased [32]. On corelating the sub-domains of Family Assessment Device with Children Depression Inventory, we found significant correlation between the affective responsiveness and affective involvement with depression scores, suggesting that people with experience of inappropriate affect among the family members and unhealthy affective involvement (with even possibly alexithymia) [33], have high depression scores.

We found that when families lack problem solving attitude, it impacts negatively on child's cognitive development and capabilities of dealing with life challenges resulting in decline in physical functioning and somatization complaints. When communication style among the family members is better and healthy it leads to less difficulties in the social engagement with others. With better defined roles in the family, we can have better expression of emotion and lastly, better the behavioural standards at home, lesser problematic behaviours are observed in school [34]. Research has shown that a child diagnosed with depression has an increased risk of developing depression in his or her adulthood. However, although there were substantial evidences in the continuity of depression from adolescence to adulthood, the consistency in the result in the continuity from pre-pubertal to adulthood is less. Thus, warranting a closer look in the transitional phases of life along with emphasis on emotional change that come with it [35]. Thus, all the above findings clearly show us how the family dynamics with regards to interactive relationships and emotional involvement with each other have a great impact on the overall development of a child and that, how these learned skills and experiences help them in various aspects of their day to day functioning and future challenges within the family and in the outside world. Also, when components of family dynamics are affected, it results in rise in depressive symptoms, which seemed to reflect more in affected female children.

To conclude, our study had $60 \%$ female population and we had $56.7 \%$ population who belonged to the age group between 14 to 17 years. Females showed slightly higher scores on the depression scale, and unhealthy functioning on four out of seven sub-domains of the family assessment device i.e. problem solving, roles, affective responsiveness and behavioural control. Also, we observed that when families lack problem solving attitude, it impacts negatively on child's cognitive development and capabilities of dealing with life challenges resulting in decline in physical functioning and somatization complaints. We also found that communication style among the family members have an impact on child's other social engagements. When roles in the family are better defined, then the emotional quality of life is positively 
influenced. When behavioural standards at home are better, lesser problematic behaviour was observed in school. Children with better affective expression of emotions and better affective involvement had lesser scores on depressive scale. We observed that, in our study population, children belonging to the age group between 14 to 17 years showed hampered physical as well as emotional, social and school functioning, in comparison with the younger group. On, children's global assessment scale, males mostly belonged to the category of some problem and some noticeable problem, both in which single or some aspects of social functioning are affected but the overall general functioning is good, which means that there are chances of depression in them going unnoticed.

\section{Limitations and Implications of our study}

Our study was a cross sectional study. It was a biased hospital sample, all being referred for academic difficulties. We excluded children with co-morbidities so the effects of co-morbidities were not evaluated. Last but not the least, we had a small sample size, a larger sample would lead to a more generalizable result. The implicates, that advocacy and awareness in both schools and communities is essential to diagnose childhood depression early, so intervention can be planned early. Older adolescents specifically, must be regularly screened for the same. Family dynamics do play a role in childhood depression, and these must be included in intervention strategies. Life skill development programs should include families to involve them in maintaining healthy relationships and communications styles, as well as use problem solving and adequate role definition as a preventive strategy.

\section{REFERENCES}

1. Reddy MS. Depression - the disorder and the burden. Indian J Psychol Med 2010;32(1):1-2.

2. Gotlib IH, Hammen CL, editors. Handbook of depression. Guilford Press; 2008.

3. Williams SB, O'Connor EA, Eder M, Whitlock EP. Screening for child and adolescent depression in primary care settings: a systematic evidence review for the US Preventive Services Task Force. Pediatrics 2009;123(4):e716-35.

4. American Academy of Child and Adolescent Psychiatry (AACAP). The Depressed Child: Facts for Families; 2008.

5. Jacob KS, Bhugra D, Lloyd KR, Mann AH. Common mental disorders, explanatory models and consultation behaviour among Indian women living in the UK. J Royal Soc Med 1998;91(2):66-71.

6. Karasz A. Cultural differences in conceptual models of depression. Soc Sci Med 2005;60(7):1625-35.

7. Kessler RC, Avenevoli S, Merikangas KR. Mood disorders in children and adolescents: an epidemiologic perspective. Biol Psychiatry 2001;49(12):1002-14.

8. Lewinsohn PM, Essau CA. Depression in adolescents. In: Gotlib IH, Hammen CL, eds. Handbook of Depression. New York, NY: Guilford Press; 2002. Pp 541-59.

9. Giaconia RM, Reinherz HZ, Silverman AB, Pakiz B, Frost AK, Cohen E. Ages of onset of psychiatric disorders in a community population of older adolescents. J Am Acad Child Adolesc Psychiatry 1994;33(5):706-17.

10. Hankin BL, Abramson LY, Moffitt TE, Silva PA, McGee R, Angell KE. Development of depression from preadolescence to young adulthood: emerging gender differences in a 10-year longitudinal study. J Abnorm Psychol 1998;107(1):128-34.

11. Weissman MM, Warner V, Wickramaratne P, Moreau D, Olfson M. Offspring of depressed parents: 10 years later. Arch Gen Psychiatry 1997;54(10):932-40.

12. Newman DL, Moffitt TE, Caspi A, Magdol L, Silva PA, Stanton WR. Psychiatric disorder in a birth cohort of young adults: prevalence, comorbidity, clinical significance, and new case incidence from ages 11 to 21 . J Consult Clin Psychol 1996;64(3):552-6.

13. Puig-Antich J, Goetz D, Davies M, Kaplan T, Davies S, Ostrow L, Asnis L, Twomey J, Iyengar S, Ryan ND. A controlled family history study of prepubertal major depressive disorder. Arch Gen Psychiatry 1989;46(5):406-18.

14. Bhatia MS, Shashi K, Bhatia SC. Childhood and adolescent depression. Am Fam Physician 2007;75(1):7380.

15. WHO. WHO Kobe. [online] WHO Kobe. Available at: https://extranet.who.int/kobe_centre/en [Accessed 27 Nov. 2018]. 
16. Birmaher B, Brent DA, Benson RS. Summary of the practice parameters for the assessment and treatment of children and adolescents with depressive disorders. J Am Acad Child Adolesc Psychiatry 1998;37(11):12348.

17. American Psychiatric Association. Diagnostic and Statistical Manual of Psychiatric Disorders $-5^{\text {th }}$ edition. American Psychiatric Publishing; 2013.

18. Finch AJ, Saylor CF, Edwards GL. Children's depression inventory: sex and grade norms for normal children. J Consult Clin Psychol 1985;53(3):424-5.

19. Finch Jr AJ, Saylor CF, Edwards GL, McIntosh JA. Children's Depression Inventory: Reliability over repeated administrations. J Clin Child Psychol 1987;16(4):339-41.

20. Epstein NB, Baldwin LM, Bishop DS. The McMaster family assessment device. J Marital Fam Ther 1983;9(2):171-80.

21. Miller IW, Epstein NB, Bishop DS, Keitner GI. The McMaster family assessment device: reliability and validity. J Marital Fam Ther 1985;11(4):345-56.

22. Varni JW, Seid M, Rode CA. The PedsQL ${ }^{\mathrm{TM}}$ : measurement model for the pediatric quality of life inventory. Med Care 1999;2:126-39.

23. Varni JW, Seid M, Kurtin PS. PedsQL ${ }^{\mathrm{TM}}$ 4.0: Reliability and validity of the Pediatric Quality of Life Inventory ${ }^{\mathrm{TM}}$ Version 4.0 Generic Core Scales in healthy and patient populations. Med Care 2001;39(8):80012.

24. Shaffer D, Gould MS, Brasic J, Ambrosini P, Fisher P, Bird H, Aluwahlia S. A children's global assessment scale (CGAS). Arch Gen Psychiatry 1983;40(11):1228-31.

25. Lundh A, Kowalski J, Sundberg CJ, Gumpert C, Landén M. Children's Global Assessment Scale (CGAS) in a naturalistic clinical setting: Inter-rater reliability and comparison with expert ratings. Psychiatr Res 2010;177(1-2):206-10.

26. Dopheide JA. Recognizing and treating depression in children and adolescents. Am J Health Syst Pharm 2006;63(3):233-43.

27. Rutter M, Kim- Cohen J, Maughan B. Continuities and discontinuities in psychopathology between childhood and adult life. J Child Psychol Psychiatry 2006;47(3- 4):276-95.

28. Danese A, Moffitt TE, Harrington H, Milne BJ, Polanczyk G, Pariante CM, Poulton R, Caspi A. Adverse childhood experiences and adult risk factors for age-related disease: depression, inflammation, and clustering of metabolic risk markers. Arch Pediatr Adolesc Med 2009;163(12):1135-43.

29. Crowe M, Ward N, Dunnachie B, Roberts M. Characteristics of adolescent depression. Int J Ment Health Nurs 2006;15(1):10-8.

30. Arnett JJ. Adolescence and emerging adulthood. Boston, MA: Pearson; 2014.

31. Gil-Rivas V, Prause J, Grella CE. Substance use after residential treatment among individuals with cooccurring disorders: The role of anxiety/depressive symptoms and trauma exposure. Psychol Addict Behav 2009;23(2):303-14.

32. Birmaher B, Ryan ND, Williamson DE, Brent DA, Kaufman J, Dahl RE, Perel J, Nelson B. Childhood and adolescent depression: a review of the past 10 years. Part I. J Am Acad Child Adolesc Psychiatry 1996;35(11):1427-39.

33. Brent DA, Birmaher B. Adolescent depression. New Engl J Med 2002;347(9):667-71.

34. Geller B, Zimerman B, Williams M, Bolhofner K, Craney JL, DelBello MP, Soutullo CA. Diagnostic characteristics of 93 cases of a prepubertal and early adolescent bipolar disorder phenotype by gender, puberty and comorbid attention deficit hyperactivity disorder. J Child Adolesc Psychopharmacol 2000;10(3):157-64.

35. Kench S, Irwin HJ. Alexithymia and childhood family environment. J Clin Psychol 2000;56(6):737-45.

$$
\begin{aligned}
& \text { Acknowledgements - Nil } \\
& \text { Source of Funding - Nil } \\
& \text { Conflict of Interest - Nil }
\end{aligned}
$$

